\title{
ANÁLISE TÉCNICA DE LAJES MACIÇAS PRÉ-MOLDADAS DO TIPO IÇADA APLICADAS EM EDIFICAÇÕES DE MÚLTIPLOS PAVIMENTOS
}

\author{
Jamiro Godinho da SILVA ${ }^{1}$ \\ Márcio Luiz de MOURA ${ }^{2}$ \\ Dejanir José CAMPOS JÚNIOR ${ }^{3}$
}

\begin{abstract}
${ }^{1}$ Graduando em Engenharia Civil - Faculdade Pitágoras, Campus Betim Minas Gerais. E-mail:jamirosilva@ hotmail.com
${ }^{2}$ Orientador e professor da Faculdade Pitágoras, campus Betim. E-mail: marcioluiz@yahoo.com.br

${ }^{3}$ Coorientador e professor da disciplina de TCC nos cursos de Engenharia Civil, Produção, Ambiental e Química da Faculdade Pitágoras, campus Betim. E-mail: dejanircampos@gmail.com
\end{abstract}

\begin{abstract}
RESUMO: Atualmente a construção civil passa por uma fase de muitas inovações, o que resulta no desenvolvimento de novas tecnologias construtivas e qualificação dos envolvidos no processo executivo, em atendimento a essas novas necessidades. Neste caso, o presente estudo se baseou na análise construtiva e técnica de lajes maciças pré-moldadas, dotadas de dispositivos de içamento, para edificações residenciais de múltiplos pavimentos. Assim, diante a escolha desta parte constituinte do sistema estrutural, com a função de fornecer a seus usuários conforto térmico e acústico, segurança e gerar na estrutura, como um todo, um enrijecimento com o travamento dos planos de alvenaria, pilares e vigas com este elemento, procurou-se destacar aspectos executivos de tal tipologia bem como apresentar os custos envolvidos para sua execução. Esse tipo de laje apresentou características vantajosas, em comparação com tipologias mais tradicionalistas, pois apresenta alta produtividade, alta rotatividade na pista de produção das lajes, utilização de pouca mão de obra qualificada e um acabamento de alta qualidade. Assim, o processo garante uma obra visualmente mais limpa, devido a redução de resíduos e eliminação das etapas de escoramento, pois as lajes são içadas e posicionadas apenas quando as mesmas já apresentam resistência mínima para realização das manobras de elevação. O trabalho ainda apresentou como objeto de estudo o Residencial Fontana Biasca, que utilizou esta tipologia construtiva, o que permitiu realizar sua caracterização nesse tipo de obra residencial.
\end{abstract}

Palavras-chave: Laje - Maciça - Pré-Moldadas.

\section{TECHNICAL ANALYSIS OF PRECAST SLABS APPLIED IN MULTIPLE FLOORS BUILDINGS}

\begin{abstract}
Currently the building is undergoing a period of many innovations, resulting in the development of new building technologies and qualification of those involved in enforcement proceedings, in response to these new needs. In this case, the present study was based on constructive and technical analysis of precast solid slabs, equipped with lifting devices, for residential buildings with multiple floors. Thus, before choosing this constituent part of the structural system, with the task of providing its users thermal and acoustic comfort, safety and generate the structure as a whole, one with the lock stiffening of masonry planes, columns and beams with this element, we tried to highlight executives aspects of such type and present the costs involved in its implementation. This type of slab presented advantageous features compared to more traditional types, because of its high productivity, high turnover in the production of floor slabs, use low-skilled labor and a high quality finish. Thus, the process provides a more visually clean work due to reduced waste and disposal stages of the brace, since the slabs are lifted and positioned just when they already have minimal resistance for performing the lifting maneuvers. The work also presented as an object of study the Residential Fontana Biasca, who used this building typology, which allowed its characterization in this type of residential work.
\end{abstract}

Keywords: Slab - Mass - Pre-molded.

\section{INTRODUÇÃO}

Nos últimos anos, os fatores econômicos do Brasil estão afetando diretamente a construção civil de forma positiva, alguns dos motivos para que isso aconteça são os incentivos fiscais, programas de financiamento de fácil acesso e principalmente pelas políticas de disponibilização de habitações de interesse social, que atualmente é destinada a populações de baixa renda e com condições precárias de habitação. Com isso, o governo federal através do Programa de Aceleração do Crescimento (PAC) criou o programa Minha Casa Minha Vida (MCMV), que segundo o MINISTÉRIO DAS CIDADES (2012) "Tem por objetivo promover a produção ou aquisição de novas unidades habitacionais, ou a requalificação de imóveis urbanos, para famílias com renda mensal de até $\mathrm{R} \$ 5.000,00 \%$. Além de 
todos os aspectos que incentivam o ramo da construção civil, outros aspectos que vêm ganhando notoriedade são: desenvolvimento de novas tipologias, a diminuição de valores, redução do tempo de execução e aumento de produtividade que garanta uma viabilidade técnica econômica para o construtor e segurança aos usuários. Uma maneira para que isso ocorra são os estudos realizados sobre os diferentes métodos de construção e implantação de lajes que podem favorecer em todos os aspectos como redução de tempo, valor acrescido na obra, enrijecimento da estrutura e aumento da produtividade. As lajes ou placas, que são partes constituintes dos sistemas estruturais, podem ser definidas, segundo a NBR 6118 (2003), como “elementos de superfície plana sujeitos principalmente a ações normais a seu plano" ou como "obra contínua de concreto armado, a qual constitui sobrado, teto de um compartimento ou piso" (Aurélio, 1999). Suas principais funções são: proteção, conforto térmico e acústico e ocasionar o enrijecimento da estrutura. São elementos que podem ser aplicadas como forro no caso de uma habitação térrea e piso para construções assobradadas ou de múltiplos pavimentos. Existem diversos tipos de lajes que podem variar de acordo com o projeto para uma melhor aplicação das mesmas. As lajes foram divididas em maciças e pré-moldadas, para facilitar o desenvolvimento do trabalho.

As maciças são lajes feitas totalmente "in loco", normalmente a partir de formas de madeira, onde é colocada a armadura e feito a concretagem. Esse sistema ocasiona uma fissuração baixa e é capaz de vencer grandes vãos. As lajes maciças têm como exemplo a cogumelo que é a apoiada diretamente sobre os pilares, não tendo a necessidade de vigas para o apoio da mesma e a nervurada. Laje cogumelo pode ser chamada também de laje lisa, é composta por placas estruturais totalmente realizadas "in loco". Não havendo a necessidade de serem apoiadas por vigas, elas distribuem sua carga diretamente nos pilares, a armadura em sua maioria é colocada sobre os apoios, ocasionando uma melhor distribuição das cargas exigidas. Laje nervurada é um sistema inteligente para vencer grandes vãos, pois ela acaba possuindo uma inércia grande com o seu preenchimento (normalmente realizado com isopor) gera nervuras na peça que posteriormente é realizado a armação da armadura em uma ou duas direções antes da concretagem, solidificando a estrutura. Esse método possui uma vantagem de ser economicamente viável, pois diminui o consumo de concreto nas regiões tracionadas e preenche totalmente as regiões comprimidas. As prémoldadas são estruturas onde se dispensa o uso de formas pois elas chegam prontas ou semi-prontas para colocação no local de destino, elas podem ser compostas por placas ou painéis. Esse sistema de construção é utilizado pois a execução é realizada com uma maior praticidade e rapidez, dispensando ou diminuindo o fluxo de mão de obra como carpinteiros, escoradores e armadores. Exemplos como treliça com lajota ou isopor, painel treliçado, painel de concreto e alveolar. Para o trabalho foi realizado um estudo sobre as lajes pré-moldadas içadas com relação a execução e seus aspectos técnicos. O estudo demonstrou as facilidades de planejamento, execução, produtividade e rotatividade, ocasionando assim um processo simples e prático sem a necessidade de mão de 
obra especializada para sua construção, além de deixar a obra mais rápida e limpa sem a necessidade da espera do tempo de cura, que é feito nas pistas de concretagem, que por sua vez chega ao destino final já com a resistência totalmente ou parcialmente completa evitando assim o uso de escoras. O presente estudo se justifica por apresentar novas tipologias construtivas que proporcionam uma menor geração de resíduos, um melhor aproveitamento de recursos e um aumento significativo de produtividade, a custos similares se comparados com tipologias mais tradicionalistas. Tal situação, parte do pressuposto que soluções como estas, são consideradas racionalizadas, pelas características apresentadas. Outro ponto relevante remete-se ao valor econômico, que dependendo do volume, pode gerar um custo similar ou abaixo dos outros modelos de lajes além das facilidades que a mesma pode gerar a toda construção.

\section{OBJETIVO}

O objetivo principal do estudo é fazer uma análise sobre a viabilidade técnica, construtiva e econômica das lajes maciças içadas. Para alcançar o objetivo principal foram apresentados os seguintes objetivos: Demonstrar as principais dificuldades executivas nas fases de planejamento e execução das obras;Identificação de como ocorre a adaptação da laje com a estrutura do prédio;Análise e apresentação sobre a qualificação dos colaboradores para a confecção e lançamento da laje;Mostrar o custo dos matérias, equipamentos e mão de obra por metro quadrado da laje maciça pré-moldada içada.

\section{METODOLOGIA}

O início do estudo se deu por uma análise dos aspectos técnicos como o processo de execução da laje, montagem da estrutura, lançamento e colocação como produto final. A realização desse estudo se deu na obra da MRV ENGENHARIA, localizada no bairro Fonte Grande, cidade de Contagem, no estado de Minas Gerais. Os processos de verificação nos canteiros de obras ocorreram de novembro de 2014 a abril de 2015 e foram realizados anotações e fotos para o desenvolvimento do estudo sobre execução de lajes maciças içadas. Após a verificação em obra foi realizado um embasamento teórico sobre acabamento da superfície, cuidados com o içamento para que não ocorra o rompimento ou a aparição de trincas na estrutura e a importância do local de destino da laje estar em nível para evitar problemas futuros com a aparição de rachadura e desníveis nas lajes.

\section{REVISÃO BIBLIOGRÁFICA}

\subsection{ESTUDO PRELIMINAR E ANTEPROJETO}

Nas etapas de estudos preliminares e no anteprojeto são avaliadas quais as tipologias dos empreendimentos que serão executadas, se os mesmos serão reforma construção ou demolição. Ainda nestas etapas, é determinado o tempo para construção, aspectos financeiros, disponibilização de recursos de prestadores de serviço e de materiais. É fundamental analisar o plano diretor e a função do empreendimento, pois podem alterar o andamento da obra o que acarretará em problemas 
no serviço, despesas e descumprimento de prazos. Determinar a arquitetura da construção é fundamental, pois é necessário levantar quais tipos de carregamentos estará sujeito (alvenarias, coberturas, ação de vento, cargas concentradas, etc.).

\subsection{PROJETO}

O projeto será realizado de acordo com as informações obtidas no estudo preliminar e no anteprojeto, ele será dividido em partes gráficas e partes escritas.

Caso do concreto armado deve seguir a NBR 6118 (2003) com relação a procedimento e vida útil de projeto, conforme descrito abaixo:"Que todas as estruturas de concreto sejam projetadas e construídas de modo que, sob as influências ambientais previstas, e quando utilizadas conforme estabelecido em projeto, conservem sua segurança, estabilidade e comportamento adequado em serviço,durante o período correspondente à vida útil de projeto".A NBR 6118 (2003) define vida útil de projeto como sendo :"Período de tempo durante o qual se mantêm as características da estrutura de concreto, desde que atendidos os requisitos de uso e manutenção prescritos pelo projetista e construtor, bem como de execução dos reparos necessários, decorrentes de eventuais danos acidentais".

\subsubsection{PARTES GRÁFICAS}

Como parte constituinte dos projetos, devem ser disponibilizados no momento da execução, segundo Azeredo (1997):
Plantas baixas;

a) Cortes transversais e longitudinais;

b) Fachadas - projeções verticais no exterior da construção;

c) Detalhes arquitetônicos;

d) Infra e superestruturas de concreto, madeira e metálica;

e) Instalações elétricas;

f) Instalações hidrossanitárias;

g) Impermeabilizações e

h) "Cronograma físico-financeiro"

Neste caso, segundo o mesmo autor as plantas baixas tratam-se de:

"Projeções horizontais onde se determina a largura das paredes, vãos de porta, janela ou corredores, tipos de piso, distribuição dos moveis e determinação do tamanho dos cômodos"Além de apresentar as principais linhas de eixos transversais e longitudinais.Já os "cortes transversais são projeções verticais longitudinais ou transversais para determinação do pé direito, altura de portas e janelas, paredes, vigas, colunas, espessura da laje, do piso e do forro" (AZEREDO, 1997). Os detalhes têm a função de proporcionar uma melhor visualização de uma peça ou elemento da construção, onde é realizada uma ampliação, deixando as características mais perceptíveis.

As estruturas são representadas graficamente como elementos que podem variar seu material de acordo com a tipologia construtiva adotada, podendo ser de concreto armado, madeira, aço ou estruturas mistas. No caso dos projetos estruturais, as plantas de fôrmas de madeira, posicionamento e dimensões das barras metálicas 
que compõem a armadura também devem ser detalhadas neste tipo de apresentação.

As instalações elétricas bem como as instalações hidrossanitárias, que representam desde a passagem da fiação elétrica, pontos de iluminação até tubulações de água fria, quente, esgoto e águas pluviais devem ser demonstradas de acordo com a tipologia adotada. Cabe ressaltar que, para tais projetos é indispensável a compatibilização dos mesmos com os projetos estruturais, visto que tais interferências podem dificultar a execução desta etapa.

É necessária a compatibilização dos projetos, pois no caso da laje esse processo determinará a abertura dos shafts, passagens de conduítes, distribuição das ferragens, tubulações de água fria e quente, hidrossanitárias e junção das placas de concreto, isso para analisar e verificar possíveis erros de projetos que possam atrapalhar a execução.

Outra etapa de extrema importância para o desenvolvimento dos projetos é a elaboração do cronograma físico-financeiro, que segundo Azeredo (1997) trata-se de: "Um calendário gráfico tão rigoroso quanto possível onde se prevê a época dos eventos das atividades e estabelece também as datas de suprimentos financeiros".Para elaboração do cronograma há necessidade de ter o conhecimento dos seguintes aspectos, segundo o mesmo autor:
a) Quantidade dos diversos serviços;
b) Coeficiente de produção;
c) Equipamento a ser utilizado;
d) Disponibilidades financeiras;
e) Padronização dos trabalhos.

\subsubsection{MEMÓRIA, ESPECIFICAÇÕES TÉCNICAS, LAUDOS E DEMAIS DOCUMENTAÇÕES}

Os memoriais, especificações técnicas, laudos e demais documentações são partes complementares a todo projeto. Tais documentações devem apresentar, segundo Azeredo (1997) "as soluções encontradas e porquê da utilização de cada escolha feita para o dimensionamento do projeto ou do tipo de execução adotada e orçamento que deve constar um custo estimado total da obra com quantitativo de materiais a serem utilizados com seus respectivos preços unitários, tanto para compra quanto para instalação, e impostos".

\subsection{LAJES}

Segundo Bastos (2006) "as lajes são os elementos planos que se destinam a receber a maior parte das ações aplicadas em uma construção. As ações são comumente perpendiculares ao plano da laje, podendo ser divididas em: distribuídas na área, distribuídas linearmente ou forças concentradas.

As ações são normalmente transmitidas para as vigas de apoio nas bordas da laje, mas eventualmente também podem ser transmitidas diretamente aos pilares".

Há inúmeros tipos e formas de se fazer uma laje, mas as mais comuns são: maciça apoiada nas bordas, nervurada, lisa e cogumelo. As lajes maciças são lajes onde não existem vazios e são apoiadas em vigas nas bordas. Já as lajes cogumelo e lisa apesar de também não terem vazios, diferentemente da maciça, são apoiadas diretamente nos pilares. 
Existem diversos modelos de lajes, onde cada uma é dotada de características que se adequam a um ou mais tipos de estruturas.

\subsubsection{LAJES COGUMELOS}

Utilizada em locais onde não deve ocorrer obstrução da visão compilares ou vigas, tendo como exemplo teatros e cinemas;

Lajes cogumelo são lajes apoiadas diretamente em pilares com capitéis, enquanto lajes lisas são as apoiadas nos pilares sem capitéis. (NBR 6118, 2003).

Conforme figura 1:

Figura 1: Laje do tipo cogumelo

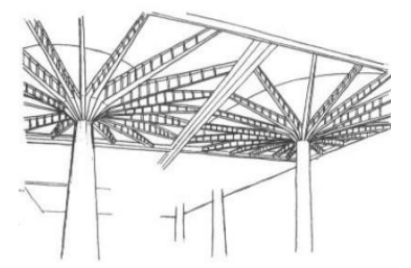

Fonte: REDETC

\subsubsection{LAJES LISAS}

Utilizadas em locais onde deve ter acesso livre, assim como em barracõese edifico garagens.

As lajes lisas por se apoiarem diretamente nos pilares apresentam a eliminação de grande parte das vigas, sendo sua principal vantagem em relação à maciça embora por outro lado tenha maior espessura. É usual em qual quer tipo de edificação seja ela pequena, média e de grande porte, apresentando também, maior rapidez de construção, como vantagens, mas, no entanto são suscetíveis a maiores flechas.

\subsubsection{LAJES MACIÇAS}

Obras de grande porte, usualmente utilizadas em edifícios que possuem cômodos de grande extensão.

Com espessura variável entre $7 \mathrm{~cm}$ e 15 $\mathrm{cm}$, as lajes maciças são comuns em edifícios de pavimentos e de obras de grande porte como escolas, hospitais, industrias, pontes e etc. De modo geral, não se usa em obras residenciais e ou outras de pequeno porte, por nesse tipo de construção ser mais vantajoso, a utilização de lajes nervuradas pré-fabricadas tipo treliça, devido ao custo e facilidade de construção.

\subsubsection{LAJES NERVURADAS}

Lajes nervuradas são as lajes moldadas no local ou com nervuras pré-moldadas, cuja zona de tração para momentos positivos está localizada nas nervuras entre as quais pode ser colocado material inerte. (NBR 6118, 2003).

Podendo também ser feito lajes nervuradas moldadas in loco sem material de enchimento, utilizando moldes plásticos removíveis. As formas plásticas reduzem o custo da forma, o tempo de execução e facilitam a construção das lajes nervuradas.

\subsubsection{LAJES TRELIÇADAS}

As lajes pré-fabricadas tipo treliça onde a armadura tem o desenho de uma treliça espacial, é muito usada em construções de residenciais de pequeno porte, e vem ganhado maior espaço até mesmo nas obras de edifícios de baixa altura, 
devido, principalmente, ao bom comportamento estrutural e facilidade de execução.

O uso das treliças pré-fabricadas traz diversos benefícios ao processo construtivo como redução do escoramento e formas, restringindo a necessidade de utilização de madeira, economia de aço, concreto, menor peso próprio e a capacidade de vencer grandes vãos.

A laje treliça da com lajotas de cerâmica são montadas de forma a intercalar uma treliça préfabricada, apoiada nas vigas ou paredes de um lado ao outro, com uma fileira de lajotas apoiada nas treliças, assim sucessivamente até cobrir todo pano de laje a ser feita conforme a figura 6, por fim é jogada uma camada de concreto denominada capa.

Figura 2: Laje treliçada com lajotas cerâmicas

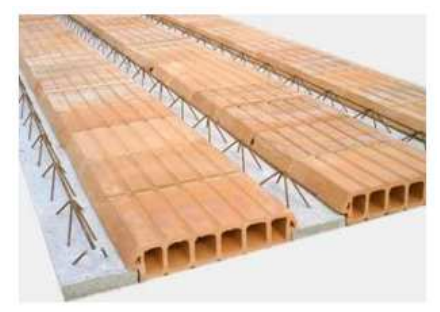

Fonte: Aprenda a Construir e Reformar

As lajes podem ser armadas em uma ou duas direções. No caso da armação unidirecional, as treliças pré-fabricadas são postas em apenas uma direção, descarregando suas cargas em dois apoios. De acordo com o vão, as treliças préfabricadas são postas na direção transversal à direção principal, com o único intuito de travamento das nervuras principais.

Por outro lado as lajes bidirecionais são concebidas para assim distribuir as cargas, e por esse motivo apresentam menores esforços em cada direção, podendo ser feitas com alturas de laje menores.
No sistema de lajes treliçadas o uso do isopor (E.P.S.) substitui com vantagens as lajotas cerâmicas e ou de concreto, por ser um material muito leve, possuir resistência mecânica boa, funcionar como isolante térmico e acústico e ter maior facilidade para recortes nas tubulações e cantos irregulares. Na figura 3 é demonstrado esse sistema.

Figura 3: Laje treliçada com EPS

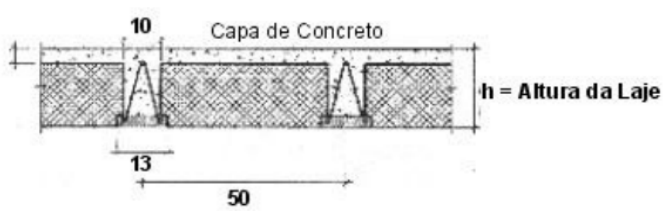

Fonte: Laje Santa Inês, 2011.

\subsection{PROJETO DE LAJES MACIÇAS IÇADAS}

A realização da compatibilização dos projetos envolvidos como hidráulica, elétrica, estrutura, etc., é de fundamental importância para que não ocorra interferências em sua montagem e em seu formato. Na armação deve ser previsto reforços para os pontos de içamento e pontos de shafts.

Quando o içamento ocorre lateralmente é necessário montar o reforço ao longo da lateral e na base do inserto, conforme a figura 4 . Todo esse processo é para evitar que ocorra um deslizamento da fixação utilizada para o levantamento da peça e para evitar fissuras ou até mesmo o rompimento pelo excesso de carga aplicada. Deverá ser previsto pontos de recuo da laje para continuação da ferragem utilizada no graute, demonstrada também na figura 4. 
Figura 4: Detalhe do reforço do inserto e Recuo da laje para passagem de ferragem

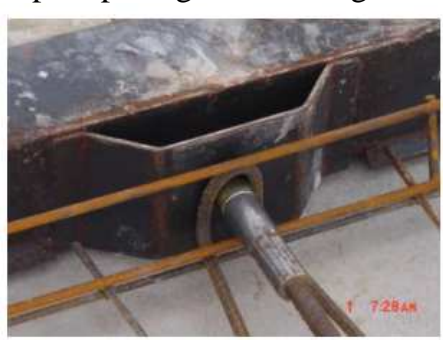

Fonte: Construtora MRV

$\mathrm{Na}$ elétrica devem ser previstos os pontos de passagem de conduítes e pontos para fixação de passantes, isso utilizado tanto na elétrica quanto na hidrosanitária demonstrados na figura 5.

Figura 5: Detalhe do passante

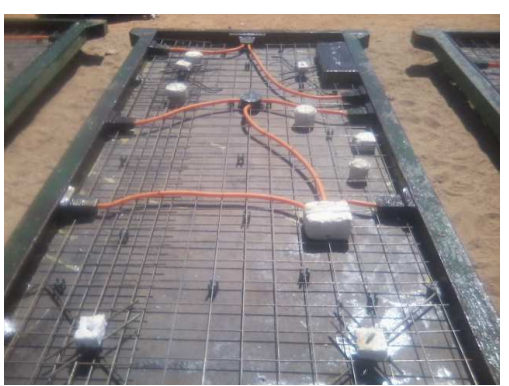

Fonte: Construtora MRV

O içamento só se torna ineficiente caso o equipamento não suportar levantar a peça, pois o tamanho da laje não limita esse processo e sim a capacidade de carga do respectivo equipamento.

É necessário prever uma pista de concretagem das lajes para que não tenha interferências e nem gere problemas na obra, devido a sua grande área de cobertura no canteiro, que varia conforme a necessidade de concretagem e estocagem das peças, que pode gerar em uma área maior ou menor conforme o projetado e estimado.

A pista para concretagem deve ser topograficamente locada, fazendo com que ela fique nivelada e posteriormente seja dado um acabamento de alta precisão conforme as peças exijam desse local. Para que o processo seja otimizado é necessário um local plano, para que ocorra uma diminuição na movimentação de terra para o nivelamento. Para a execução é necessário seguir os processos demonstradas nas figuras 6,7 , 8,9 e 10 para que possa obter uma pista ideal para a concretagem.

Figura 6: Pista locada topograficamente respeitando as interferências previstas em projeto

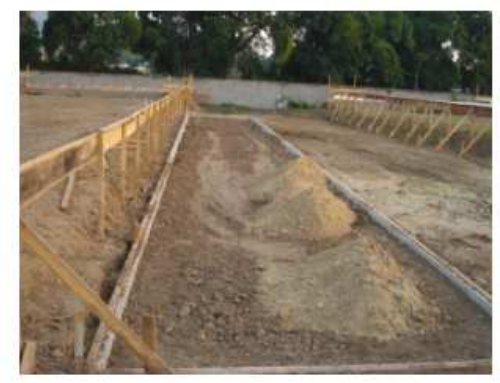

Fonte: Construtora MRV

Figura 7: Utilizar sarrafo no topo, para garantir o nível e facilitar concretagem

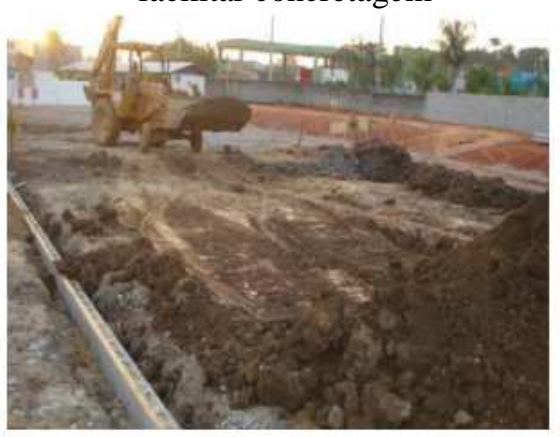

Fonte: Construtora MRV

Figura 8 - A base deve ter espessura e armação mínima e acabamento polido

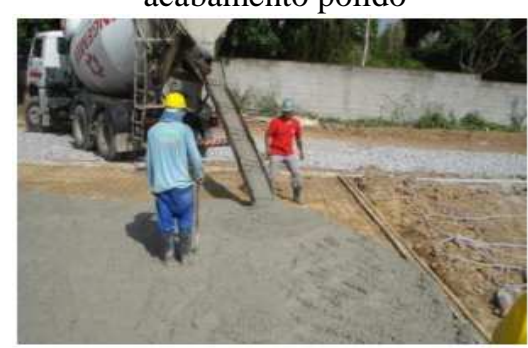

Fonte: ConstrutoraMRV 
Figura 9: Concretagem deve-se testar os acessos e realizar os ajustes necessários

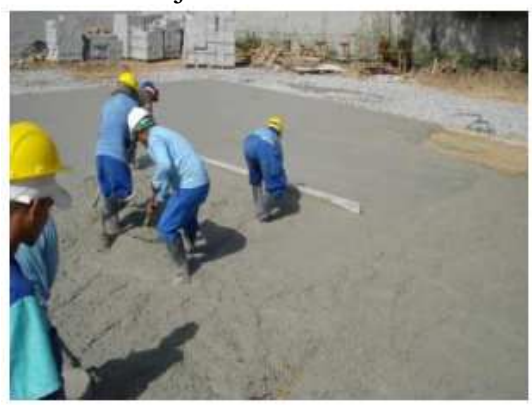

Fonte: Construtora MRV

Figura 10: Recomenda-se ter no mínimo 3 bases de cada tipo de laje necessária, sendo uma para estoque, uma para cura e uma para produção

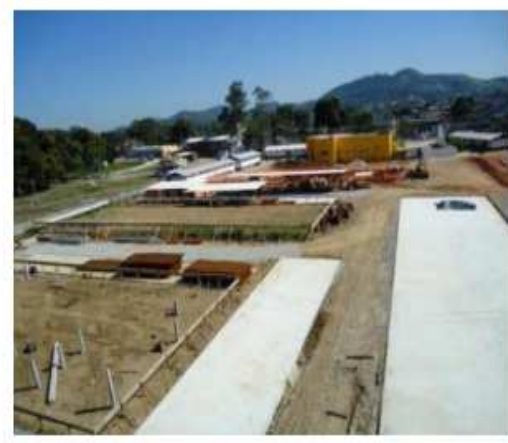

Fonte: Construtora MRV

É necessário deixar a telas de armação das lajes em uma sequência compatível com a concretagem e organizar para que as telas assim como os outros materiais utilizados para a fabricação das peças estejam próximos as pistas de concretagem para que possa haver uma facilidade na movimentação, gerando uma linha de montagem otimizada para a concretagem das placas.

Para um aumento da produtividade é utilizado um gabarito na proporção 1:1, indicando a posição da forma, das ferragens, pontos de luz, passagem das tubulações e passantes tanto na elétrica, quanto na hidráulica e hidrossanitárias, conforme demonstrado na figura 11 .
Figura 11 - Gabarito com todas as informações necessárias para fabricação da laje

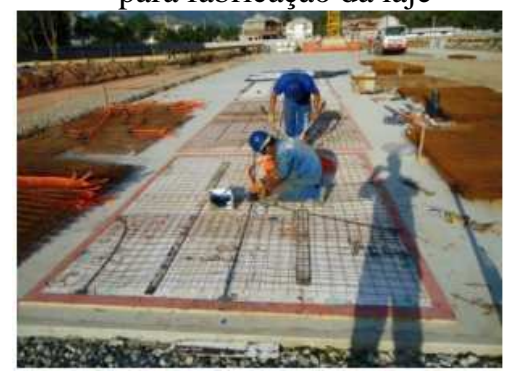

Fonte: Construtora MRV

$\mathrm{Na}$ hora da montagem da forma é necessário verificar esquadro, compatibilização dos encaixes, altura da forma e nivelamento conforme figura 13, após realizado essa etapa começa o processo de colocação da armadura, insertos, reforços, luvas, passantes e tubulações e se necessários outros especificados em projeto conforme figura 14 e 15 .

Figura 13: Verificação da forma

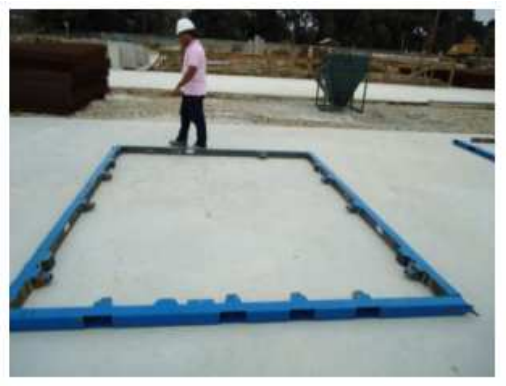

Fonte: Construtora MRV

Figura 14:Instalação dos componentes existentes na laje

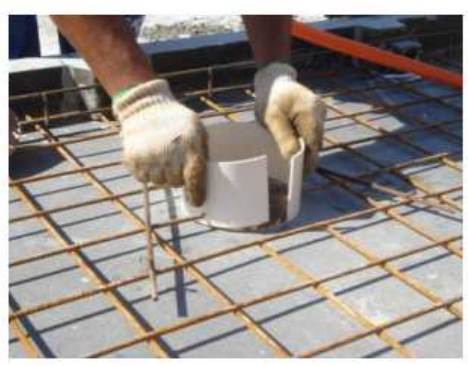

Fonte: Construtora MRV 
Figura 15 - Pista com algumas lajes prontas para receberem o concreto

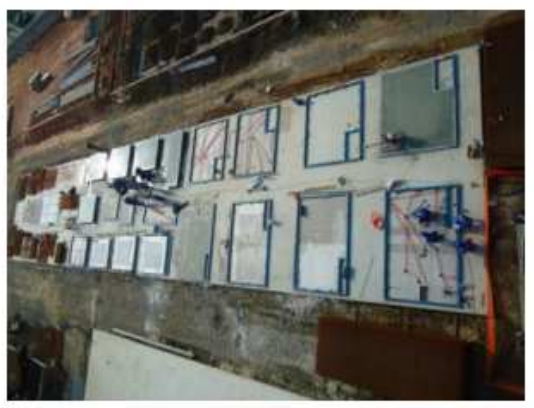

Fonte: Construtora MRV

Depois de realizada a concretagem que é repetidamente uma sobreposta a outra, gerando em uma pilha com altura máxima variando conforme for o mecanismo de concretagem das formas ou pode ser determinado conforme o previsto em projeto para que as etapas de concretagem, cura e retirada das placas não altere a rotatividade da produção das peças.

As lajes podem ser produzidas em pilhas graças aos desmoldantes que impedem o concreto fresco de se misturar, fundir, grudar ao concreto já endurecido. O desmoldante é uma composição oleosa que evita a aderência do concreto sobre o concreto e melhora também a qualidade da superfície da laje, ele deve ser passado antes da colocação dos componentes necessários na fabricação da laje como forma, armadura, entre outros.

Na forma é necessária a utilização de outro desmoldante com características que possui a função e evitar a aderência do concreto com a forma metálica, como exemplo o Rheofinish FR 350“facilita a desmoldagem, melhora a aparência da superfície do concreto, obtenção de superfícies lisas e arestas vivas, economiza tempo no preparo das formas, protege as formas,aumentando sua vida útil, altorendimento e facilidade na aplicação. (RHEOFINISH, 2012).
O processo de acabamento é necessário ser realizado assim que o concreto atinja um endurecimento capaz de suportar a movimentação da superfície, esse processo é rápido mas que pode ser alterado pela temperatura ou umidade do dia.

$\mathrm{Na}$ figura 16 foi utilizado para o dar acabamento nas lajes a Alisadora de Piso de Concreto PT 46 da PETROTEC (fabricante de equipamentos para construção) figura 20. Segundo seu manual ela possui as seguintes informações técnicas:

A Alisadora de Piso de Concreto PT 46 é um equipamento extra forte especialmente projetado para um acabamento perfeito em pisos de concreto, possui controle variável de velocidade possibilitando, assim, o ajuste das lâminas conforme as diversas necessidades de acabamento, este equipamento é conhecido também com: alisadora de concreto, alisadora de piso, acabadora de piso, acabadora de concreto, bailarina, helicóptero e bambolê. Pintura eletrostática, diâmetro da saia: $1.168 \mathrm{~mm}$, modelos disponíveis, Alisadora de piso modelo PT 46-A: equipada com motor 4 Tempos 9 HP e embreagem centrífuga.

Figura 16:Alisadora de Piso de Concreto PT 46

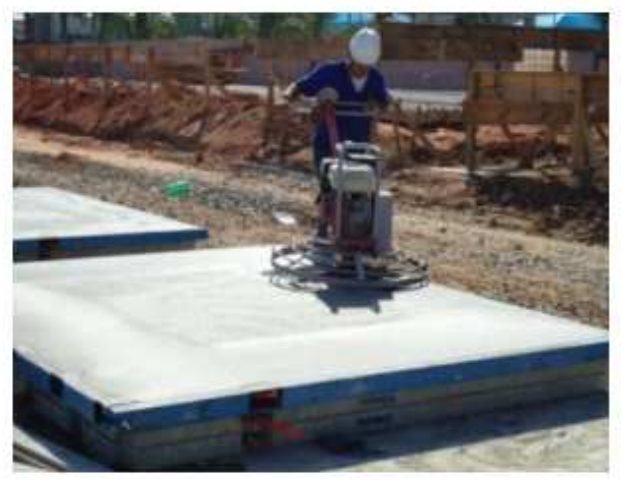

Fonte: Construtora MRV 
Figura 17 - Alisadora de Piso de Concreto PT 46

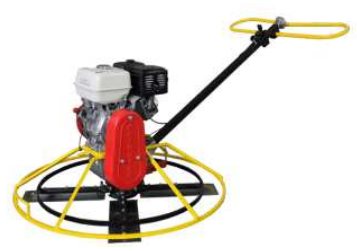

Fonte: Construtora MRV

Após a regularização e alisamento do concreto deve-se esperar o tempo de cura e posteriormente começar o processo de retirada e lançamento das placas. O início do processo se dá soltando a laje da pilha em que está localizada, isso pode ser feito através de macacos hidráulicos dispostos em torno da laje evitando que a mesma sofra trincas, em sequência é necessário fazer o içamento das placas que pode ser feito por munck, guindaste ou grua, dependendo da necessidade, esse levantamento se dá por meio de um encaixe na lateral da laje conforme a figura 18, que mostra os içadores utilizados para o levantamento da laje e é o mesmo local de macaqueio para separação das placas.O macaqueio da laje deve ocorrer simultaneamente em todos os pontos, para evitar os problemas estruturais da peça, mantendo as características conforme projetadas para desempenhar seu papel de origem, a figura 19 demonstra o modo como deve ser realizado para que ocorra êxito no processo.

Figura 18: Macaco posicionado abaixo dos içadores

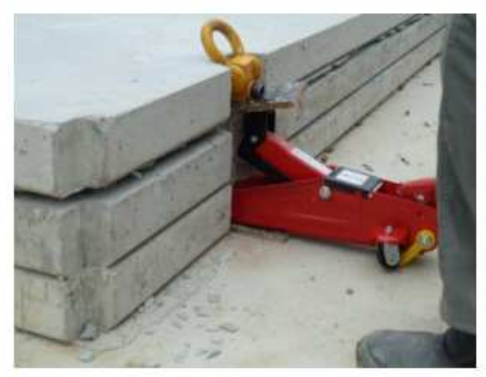

Fonte: Construtora MRV
Figura 19 - Desplacamento realizado simultaneamente por macacos hidráulicos

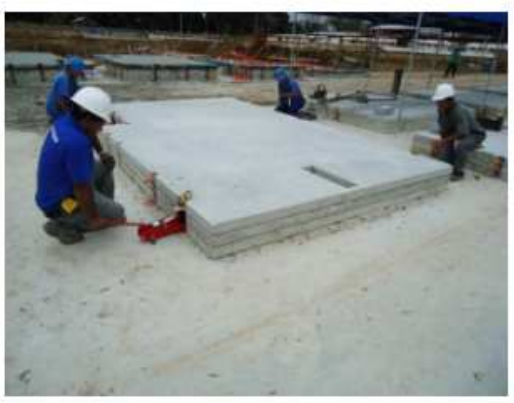

Fonte: Construtora MRV

Após o desplacamento é necessário fazer o levantamento da laje. O levantamento ocorre com a colocação dos ganchos dos cabos de aço do mecanismo de levantamento nos pontos de içamento (figura 20), após a colocação é necessário fazer a locomoção da laje da pista de estocagem para o local definido no prédio (figura 24). Para a colocação da placa na estrutura do prédio é necessário passar argamassa para que ocorra uma vedação e acomodação entre as estruturas, neste caso a laje é apoiada sobre a alvenaria estrutural conforme a figura 25 .

Figura 20: Utilização dos cabos de aço para içamento da laje

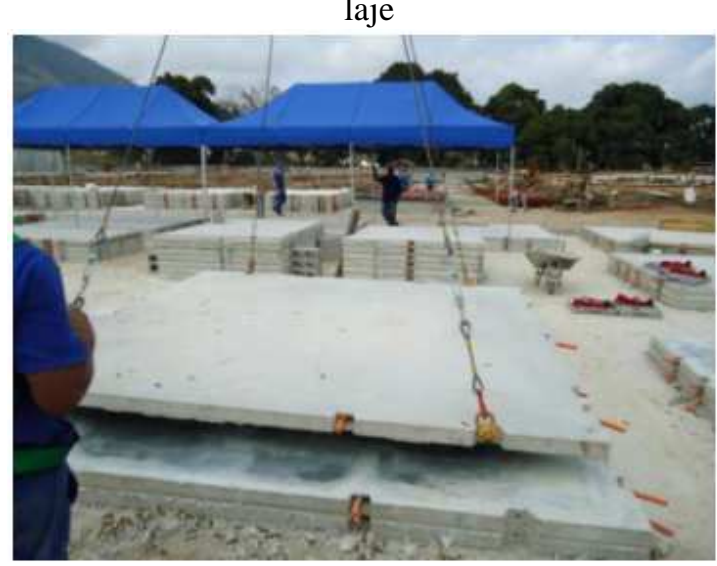

Fonte: Construtora MRV 
Figura 21: Transposição da laje da pista de estocagem para o local que ela foi projetada na estrutura do prédio

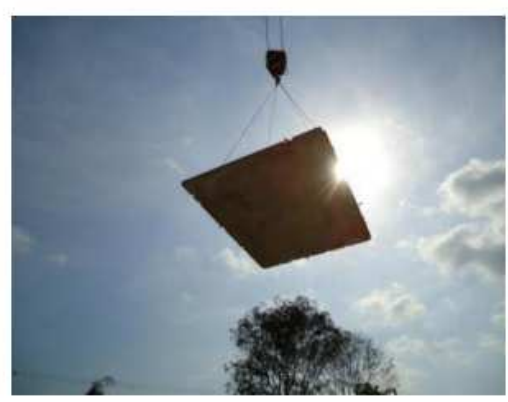

Fonte: Construtora MRV

Figura 22: Colocação da laje na estrutura de alvenaria estrutural

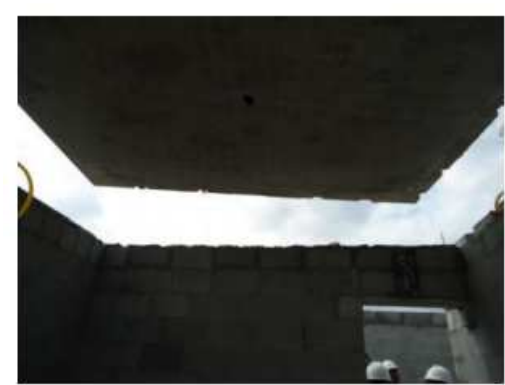

Fonte: Construtora MRV

$\mathrm{O}$ içamento das lajes pode ser realizado a partir do sétimo dia, tomando como base os ensaios realizados. Lembrando que deve ser utilizada para controle interno na obra uma ficha de concretagem, pois na mesma estálocalizada dados como data, nota fiscal entre outros dados citados. Para acompanhamento das lajes elas são marcadas conforme foi realizada na figura 24 , que possui informações como data de concretagem, local, nome da concreteira, tempo de saída da usina, tempo de termino de concretagem, resistência aos 07 e 28 dias.

Figura 23: Controle da concretagem - Data e Nota Fiscal

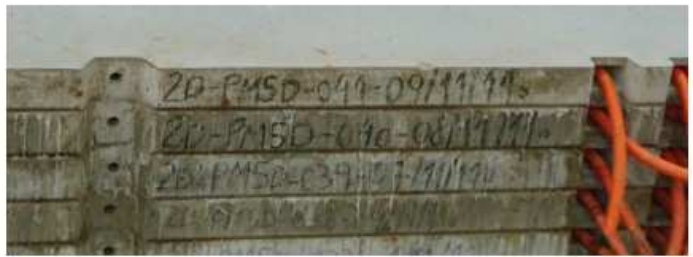

Fonte: Construtora MRV
Quando terminada a colocação de todas as lajes sobre a estrutura, é necessária conferir o nível entre elas, caso ocorra alguma diferença entre elas deve-se utilizar escoras para que o nivelamento seja perfeito como demonstrada pelo funcionário na figura 24.

Figura 24: Conferencia do nivelamento entre as lajes

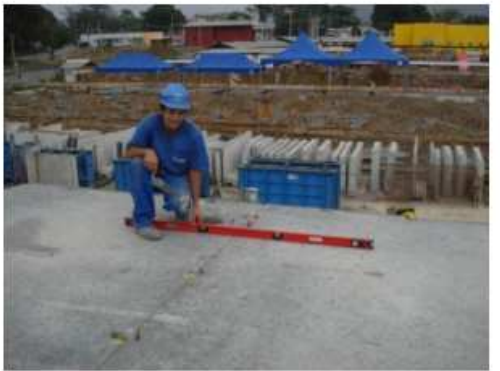

Fonte: Construtora MRV

Após conferir o nivelamento e realizar a ligação das tubulações é necessário fazer a soldagem entre as placas. A soldagem é realizada por meio do grouteamento, gerando em uma estrutura única.

É importante salientar que, para a colocação da laje na alvenaria estrutural a última fiada deve estar grouteada com as tubulações da elétrica já instaladas para ligação com a laje (figura 26). A definição básica para o grout segundo Paviart (2012) "grout é um micro concreto que serve para preencher as cavidades dos blocos onde são acomodadas as armaduras verticais ou horizontais e as amarrações das paredes através de grampos". 
Figura 25: Alvenaria grouteada e a ligação das tubulações realizada

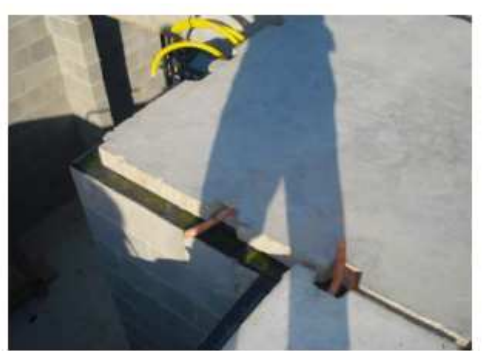

Fonte: Construtora MRV

Para encerrar o processo de execução e controle é necessário utilizar um desenho com as disposições das lajes com os respectivos dados para controle como número da laje, data, nota fiscal e o local que foi colocada.

\section{OBJETO DE ESTUDO}

Para uma melhor caracterização do presente estudo, foi escolhido um objeto de estudo com as seguintes especificações:

\subsection{CARACTERIZAÇÃO DO EMPREENDIMENTO}

Empresa Responsável - Construtora MRV;

Localidade - Contagem/MG;

Obra - Parque Fontana Biasca;

Tipologia - Vertical

Tipo de construção- Alvenaria estrutural com blocos cerâmicos;

Altura entre lajes- 2,60 m;

Número de pavimentos -4 ;

Número de apartamentos por pavimento - 4;

Composição do apartamento - 2 Quartos, 1 Sala, 1

Banheiro e 1 Cozinha;

\subsection{LAJE}

Empresa responsável - FC Pré Moldados

Localidade da empresa: Mogi Mirim/SP

Espessura da laje - $9 \mathrm{~cm}$;

Área total das lajes por apartamento - $44 \mathrm{~m}^{2}$;

Área de laje no corredor social $-6,5 \mathrm{~m}^{2}$.

\section{RESULTADOS}

As dificuldades encontradas no planejamento ocorrem principalmente por parte da logística em relação a movimentação de caminhões utilizados para concretagem, pois devem estar sempre ao alcance das formas quando a concretagem não for realizada por bombas e dos equipamentos utilizados para retirada e içamento das placas, como por exemplo muque ou guindaste. A implantação da pista de concretagem é outro problema, pois demanda de uma área para a implantação grande devido ao número de painéis que a obra necessita, além de nivelada que ocasiona muitas vezes dificuldades para sua instalação chegando ao ponto de ficar impossibilitada a implantação da mesma no canteiro de obras, ou por falta de espaço ou pela inclinação ser muito elevada.

$\mathrm{Na}$ execução os problemas ficam por conta da montagem da forma, acabamento, lançamento. Na montagem deve-se tomar cuidado com a montagem das formas, evitando a aparição de desníveis nas estruturas e cuidados com a utilização do desmoldante que deve ser totalmente passado na superfície a fim de evitar a união entre as placas na pista. 
Em dias chuvosos deve se tomar cuidados com a proteção das lajes assim que concreta das, pois pode ocasionar em uma superfície áspera. Isso ocorre, pois chuva lava o concreto retirando a nata de cimento que fica em toda superfície após a concretagem, deixando assim a agregada amostra.

No içamento, os problemas podem ocorrer na retirada da laje da pista de concretagem e na instalação da laje no prédio, esses problemas são ocasionados quando essas etapas são realizadas rapidamente sem o cuidado necessário.

Quando é necessário efetuar o desfaçamento é necessário verificar se a laje está com a superfície totalmente liberada para iça mento, pois caso não esteja pode ocorrer uma flexão do plano até a sua ruptura, isso pode ser ocasionado caso não seja efetuado a passagem do desmoldante entre as concretagens.

A instalação da laje na estrutura do prédio ocorre seguindo os procedimentos:Colocação da argamassa na superfície dos blocos para acomodação das lajes;Após a colocação dos painéis deve ser realizada a ligação entre as tubulações de elétrica; Para finalizar é realizado o grauteamento entre as laterais das lajes. Analisando os processos iniciais e finais da laje é possível determinar a utilização dos funcionários qualificados apenas para as seguintes funções:Montagem das formas - pela complexidade de deixar as formas niveladas e esquadrejadas, apesar de só existir um modo de encaixa-las; Utilização do equipamento para dar acabamento a superfície da laje - por se tratar deum equipamento motorizado, pesado e de alta rotatividade, além de ter um sentido apurado para não deixar a laje deformada; Retirar as lajes da pista de concretagem - o funcionário deve ser capacitado a realizar odesplacamento das lajes da pista de concretagem, para esse serviço é necessário verificar se ocorre o desprendimento total da superfície da laje para que não ocorra o rompimento da estrutura e nem o aparecimento de trincas; Montagem das lajes na alvenaria - se faz necessário a experiência de um funcionárioexperiente para efetuar o lançamento, por se tratar de peças de concreto robustas que necessitam obter um encaixe exato na alvenaria sem a ocorrência de pancadas ou trancos na estrutura do prédio.

O custo para confecção das formas para 16 lajes, que compõem 1 pavimento do prédio, é de $\mathrm{R} \$ 18.000,00$. Cada forma tem um reaproveitamento de aproximadamente 120 vezes. Com isso ocorre uma diluição do valor total das formas pela quantidade de reaproveitamento dela, tento então o valor de $\mathrm{R} \$ 150,00$ de forma por pavimento, o que ocasiona em um baixo valor acrescido no $\mathrm{m}^{2}$.

\section{CONSIDERAÇÕES FINAIS}

Deve ficar claro que o processo é de alta produtividade e rotatividade, então para ser executado é necessário estar com um volume alto a ser executado ou ter um planejamento para reaproveitamento das formas, afim de utilização seus principais benefícios. O processo é eficiente para obras que necessitam ser realizadas com o mínimo tempo de espera, pois a cura e o acumulo deresistência são adquiridas ainda na pista de concretagem, diferente das demais lajes efetuadas in-loco portanto ficar claro que o processo é de alta 
produtividade e rotatividade, então para ser executado é necessário estar com um volume alto a ser executado ou ter um planejamento para reaproveitamento das formas, afim de utilização seus principais benefícios. de uma execução que nãogera resíduos sólidos e nem desperdício de matérias que são previamente estimados e confeccionados para utilização.

\section{REFERÊNCIAS}

APRENDA A CONSTRUIR E REFORMAR. Lajes Pré Fabricadas. 2010. acesso em: out.2012.

ARQUITECTANDO. Matérias de construção Concreto. Disponível em:, acesso em: nov.2012.

\section{ASSOCIAÇÃO BRASILEIRA DE CIMENTO} PORTLAND. Fabricação do cimento. 2009. Disponível em: acesso em: nov.2012.

\section{ASSOCIAÇÃO BRASILEIRA DE NORMAS} TÉCNICAS. NBR 6118: Projeto de estruturas de concreto - Procedimento. Rio de Janeiro, 2003.

\section{ASSOCIAÇÃO BRASILEIRA DE NORMAS}

TÉCNICAS. NM 67: Determinação da consistência pelo abatimento do tronco. Rio de Janeiro, 1998.

AZEREDO H. A. O Edifício até sua Cobertura. Ed. Edgard Blücher Ltda. São Paulo. $2^{a}$ Ed. 1997.

BASTOS, P. S. S. Dimensionamento de Vigas de Concreto Armado à Força Cortante. Notas de aula do curso de Engenharia Civil da Universidade Estadual Paulista, Campus Bauru, 2008. Disponível em: , acesso em: out.2012.

BASTOS, P. S. S. Fundamentos do Concreto Armado. Notas de aula do curso de Engenharia Civil da Universidade Estadual Paulista, Campus Bauru, 2006. Disponível em: , acesso em: out.2012.

BAUER, L.A.F. Materiais de Construção 1. Ed. Livros Técnicos e Científicos. Rio de Janeiro. $4^{a}$ Ed. 1992.

BRASIL. MINISTÉRIO DAS CIDADES. Programa Habitacional Brasileiro. 2009. Disponível em: acesso em: nov.2012.

CURY. Laje Empilhada Produzida no Canteiro de Obras. Manual de Instrução. 2010.

DANGELO, S. Vigas de Concreto. Apostila do curso de Engenharia Civil da Universidade de Taubaté, Campus Taubaté, 2007. Disponível em: acesso em:out.2012.
FERREIRA, A. B. H. Dicionário Aurélio Básico Da Língua Portuguesa. Rio de Janeiro: Nova Fronteira, 1988.

DIVISE ENGENHARIA. Cura do concreto. 2008.

Disponível em: , acesso em: nov.2012.

EVANGELISTA, A.C. Dosagem de Concreto. Apostila do curso de Engenharia Civil da Universidade Federal do Rio de Janeiro, 2011. Disponível em: , acesso em: out.2012.

FC PRÉ-MOLDADOS. Orçamentos e Projetos. 2012.

FERRONATTO, D. S. ET ALl. Lajes: definições, aplicações e técnicas construtivas. Trabalho de alunos do curso de Engenharia Civil da Universidade Federal de Santa Catarina, 2008. Disponível em: , acesso em: out.2012.

JUNIOR, T. F. S. Estruturas de Concreto Armando. Notas de aula do curso de Engenharia Civil da Universidade Federal de Lavras. Acesso em: Nov.2012.

LAJE SANTA INÊS. Lajes Treliçadas. 2011. Disponível em: , acesso em: out.2012.

LIBANIO, M. P., ET AL. Estruturas De Concreto. Apostila do curso de Engenharia Civil da Universidade de São Paulo, 2005. Disponível em: , acesso em: Nov.2012.

PETROTEC. Manual Técnico do Proprietário Petrotec. 2012. Disponível em: . Acesso em: out.2012 PETRUCCI, E. G. Concreto de Cimento Portland. Ed. Associação Brasileira de Cimento Portland. São Paulo. 1968.

PFEIL, W. Pontes em Concreto Armado. Ed. Livros Técnicos e Científicos. $2^{a}$ Ed. Rio de Janeiro. 1980.

PORTAL DO CONCRETO. Consistência do Concreto. 2012. Disponível em: , acesso em: out.2012.

REDETC. Lajes Cogumelo. 2012. Disponível em: , acesso em: out.2012.

RHEOFINISH. Reofish 350 - Propriedades e Benefícios. 2012. Disponível em: . Acesso em: out.2012.

TANGO, C. E. S. T. Cimento Portland - Caracteristicas e Propriedades. 2012. Disponível em: , acesso em: Nov.2012.

YAZIGI, W. A Técnica de Edificar. Ed. Pini / Sinduscon SP. São Paulo. 10. ed. 2009. 